\title{
Neuroprotective effects of edaravone-administration on 6-OHDA-treated dopaminergic neurons
}

Wen Ji Yuan, Takao Yasuhara*, Tetsuro Shingo, Kenichiro Muraoka, Takashi Agari, Masahiro Kameda, Takashi Uozumi, Naoki Tajiri, Takamasa Morimoto, Meng Jing, Tanefumi Baba, Feifei Wang, Hanbai Leung, Toshihiro Matsui, Yasuyuki Miyoshi and Isao Date

Address: Department of Neurological Surgery, Okayama University Graduate School of Medicine, Dentistry and Pharmaceutical Sciences, Japan Email:Wen Ji Yuan - yuanwenji@hotmail.com; Takao Yasuhara* - tyasu37@cc.okayama-u.ac.jp; Tetsuro Shingo - shingo@md.okayama-u.ac.jp; Kenichiro Muraoka - northwestpoint107ken@yahoo.co.jp; Takashi Agari - agarit@cc.okayama-u.ac.jp;

Masahiro Kameda - mrkameda@gmail.com; Takashi Uozumi - takashi_uozumi@yahoo.co.jp; Naoki Tajiri - tajirin@md.okayama-u.ac.jp; Takamasa Morimoto - takamachan_morimori@ybb.ne.jp; Meng Jing - dr.j_meng@hotmail.com; Tanefumi Baba - babatane@is.icc.u-tokai.ac.jp; Feifei Wang - gmd19011@cc.okayama-u.ac.jp; Hanbai Leung - ileoleung@hotmail.com; Toshihiro Matsui - toshimatsui-nsu@umin.ac.jp; Yasuyuki Miyoshi - ya-miyo1@md.okayama-u.ac.jp; Isao Date - idate333@md.okayama-u.ac.jp

* Corresponding author

\section{Published: I August 2008}

BMC Neuroscience 2008, 9:75 doi:10.1 186/147/-2202-9-75
Received: 8 January 2008

Accepted: I August 2008

This article is available from: http://www.biomedcentral.com/147/-2202/9/75

(C) $2008 \mathrm{Ji}$ Yuan et al; licensee BioMed Central Ltd.

This is an Open Access article distributed under the terms of the Creative Commons Attribution License (http://creativecommons.org/licenses/by/2.0), which permits unrestricted use, distribution, and reproduction in any medium, provided the original work is properly cited.

\begin{abstract}
Background: Parkinson's disease (PD) is a neurological disorder characterized by the degeneration of nigrostriatal dopaminergic systems. Free radicals induced by oxidative stress are involved in the mechanisms of cell death in PD. This study clarifies the neuroprotective effects of edaravone ( $\mathrm{MCl}$-186, 3-methyl-I-phenyl-2-pyrazolin-5-one), which has already been used for the treatment of cerebral ischemia in Japan, on TH-positive dopaminergic neurons using PD model both in vitro and in vivo. 6-hydroxydopamine (6-OHDA), a neurotoxin for dopaminergic neurons, was added to cultured dopaminergic neurons derived from murine embryonal ventral mesencephalon with subsequet administration of edaravone or saline. The number of surviving $\mathrm{TH}$-positive neurons and the degree of cell damage induced by free radicals were analyzed. In parallel, edaravone or saline was intravenously administered for PD model of rats receiving intrastriatal 6-OHDA lesion with subsequent behavioral and histological analyses.
\end{abstract}

Results: In vitro study showed that edaravone significantly ameliorated the survival of TH-positive neurons in a dose-responsive manner. The number of apoptotic cells and HEt-positive cells significantly decreased, thus indicating that the neuroprotective effects of edaravone might be mediated by anti-apoptotic effects through the suppression of free radicals by edaravone. In vivo study demonstrated that edaravone-administration at 30 minutes after 6-OHDA lesion reduced the number of amphetamineinduced rotations significantly than edaravone-administration at 24 hours. Tyrosine hydroxylase (TH) staining of the striatum and substantia nigra pars compacta revealed that edaravone might exert neuroprotective effects on nigrostriatal dopaminergic systems. The neuroprotective effects were prominent when edaravone was administered early and in high concentration. TUNEL, HEt and Iba-I staining in vivo might demonstrate the involvement of anti-apoptotic, anti-oxidative and anti-inflammatory effects of edaravone-administration.

Conclusion: Edaravone exerts neuroprotective effects on PD model both in vitro and in vivo. The underlying mechanisms might be involved in the anti-apoptotic effects, anti-oxidative effects, and/or anti-inflammatory effects of edaravone. Edaravone might be a hopeful therapeutic option for PD, although the high therapeutic dosage remains to be solved for the clinical application. 


\section{Background}

Parkinson's disease (PD) is a neurodegenerative disorder characterized by slowly progressive degeneration of DA neurons in the substantia nigra pars compacta, with subsequent damage of nerve terminals accompanied by dopamine (DA) depletion in the striatum [1]. Although the neuropathological hallmarks of PD are well described, the etiology remains still undefined. However, accumulative evidences revealed many biochemical processes and molecular mechanisms as mediators of neuronal cell death in PD. Notably oxidative stress and mitochondrial dysfunction might be an important pillar of pathogenesis of PD [2].

6-hydroxydopamine (6-OHDA) is widely used for experimental models of PD [3]. It damages cells with dopaminergic neuronal attribute, including human neuroblastoma SH-SY5Y [4], PC12 cells derived from rat pheochromocytoma [5] and rat ventral mesencephalic neurons [6]. Furthermore, it is also a specific neurotoxin for DA neurons in vivo $[2,7]$. Intracellular lipids, proteins or DNA are damaged with consequent impairment of cell function induced by 6-OHDA. Mitochondrial oxidative phosphorylation with subsequent energy deprivation and excrement of 6-OHDA-auto-oxidation, including quinones and hydrogen peroxide $\left(\mathrm{H}_{2} \mathrm{O}_{2}\right)$ are deeply involved in the cytotoxic processes [8]. As above described, mitochondrial dysfunction and oxidative stress might play important roles in the pathogenesis of PD [2], thus indicating that the experimental model using 6-OHDA might have essential mechanisms in common with PD. Furthermore, anti-oxidant agents, such as catalase, vitamin E, N-acetyl cysteine, ascorbic acid and pyruvate might exert neuroprotection for 6-OHDA-treated DA neurons [9].

Edaravone (3-methyl-1-phenyl-2-pyrazolin-5-one) is a potent scavenger of hydroxyl radicals, and is useful for patients suffering from ischemic stroke $[10,11]$, with the involvement of peroxidation leading to neuronal cell death [12]. Neuroprotective effects of edaravone are explored using head trauma [13] and spinal cord ischemia [14]. Recent study demonstrated that edaravone suppress the production of nitric oxide and reactive oxygen species by activated microglia [15]. In both cerebral ischemia and PD, free radicals might be one of the critical pathogenesis which accelerates progression of disease. These results suggest that edaravone might have neuroprotective effects on 6-OHDA-treated DA neurons and might on slowly degenerated DA neurons in PD patients through anti-oxidative mechanisms.

In this study, first we explored the neuroprotective effects of edaravone on 6-OHDA-induced toxicity against murine ventral mesencephalic (VM) cell cultures and the underlying mechanisms. After confirming the effects in vitro, edaravone was intravenously administered to 6OHDA-lesioned PD model of rats and evaluated behaviorally and immunohistochemically.

\section{Methods \\ In vitro model of Parkinson's disease \\ Cell preparation}

Murine DA neurons were cultured as described previously with minor modifications [16]. Tissue blocks of the ventral mesencephalon containing DA neurons were dissected from murine embryo (C57/B6) on day 14 of gestation after cervical dislocation with consequent trituration into single cell suspension. Cells were plated in mixed hormone MEM (MHM) supplemented with 1\% fetal bovine serum at a density of $1 \times 10^{5}$ cells/well on poly-D-ornithine and fibronectin-coated glass slides in 24-well plates (Nunc, Frankfurt, FRG). Cultures were maintained at 37 degrees $\mathrm{C}$ in an atmosphere of $5 \% \mathrm{CO}_{2}$ plus $95 \%$ air and with $100 \%$ relative humidity. Fortyeight hours after initial plating, the medium was exchanged and the cells were used for the further experiments. The average number of mesencephalic neurons was $0.42 \pm 0.07 \times 10^{5}$ cells/well at the beginning of the experiment with $\mathrm{TH}$-immunoreactivity in $37 \pm 12 \%$ of total cells.

\section{Administration of 6-OHDA and edaravone}

Edaravone (MCI-186, 3-methyl-1-phenyl-2-pyrazolin-5one) was kindly provided from Mitsubishi Pharma (Japan). It was dissolved in $0.5 \mathrm{ml}$ of $1 \mathrm{~N} \mathrm{NaOH}$ and $8 \mathrm{ml}$ of distilled water, and adjusted to $\mathrm{pH} 7$ by addition of $1 \mathrm{~N}$ $\mathrm{HCl}$. At 48 hours after the initial plating, the cultured cells were exposed to $40 \mu \mathrm{M}$ 6-OHDA (Sigma) or PBS for 30 minutes, and then added $10^{-6}, 10^{-5}, 10^{-4}$ or $10^{-3} \mathrm{M}$ edaravone, or saline as a control at 37 degrees $\mathrm{C}$. The cells were incubated for 18 hours and developed to immunocytochemical investigations.

\section{Immunocytochemistry}

Cells were fixed with 4\% paraformaldehyde (PFA) for 30 minutes and then washed three times for 5 minutes in PBS. They were incubated overnight at 4 degrees $C$ with an antibody directed against tyrosine hydroxylase (TH, rabbit polyclonal IgG, 1: 500, Chemicon) with 10\% normal goat serum (Vector). After several rinses in PBS, cells were incubated at room temperature for 30 minutes in sheep anti-rabbit IgG FITC conjugate (1: 500, Sigma) and 4',6diamidino-2-phenylindole, dilactate (DAPI, 1: 500, Molecular Probes). The cells were then washed three times in PBS and mounted on albumin-coated slides and embedded with cover glass. After photographically captured, immunoreactive neurons were counted per high power field view selected at random ( $n=3$ in each well, $10,000 \mu \mathrm{m}^{2}$ ). Six wells were assigned to each group for statistical analyses. Control studies involved exclusion of 
primary antibody substituted with 10\% normal goat serum in PBS. No immunoreactivity was observed in these controls.

\section{TUNEL staining and HEt staining}

In order to explore the involvement of apoptosis in this study, a modified method for terminal deoxynucleotidyl transferase-mediated biotinylated UTP nick end labeling (TUNEL, Roche) and DAPI staining was also used. After edaravone $\left(10^{-6}-10^{-3} \mathrm{M}\right)$ or saline were administered into separate series of 6-OHDA-treated DA neurons, cells were fixed at 18 hours as described in the previous section. TUNEL staining was performed according to the manufacturer's instruction.

In order to detect the early production of superoxide anions after 6-OHDA addition, hydroethidine (HEt), selectively oxidized to ehidium by superoxide anions, was used. HEt ( $1 \mathrm{mg} / \mathrm{ml}$ in PBS) was administered to 6OHDA-treated DA neuronal cell culture at $0,10,20$ or 30 minutes after edaravone- or saline- administration. After 5-minute incubation with HEt, the cells were washed 3 times in PBS, fixed with PFA, washed with PBS containing DAPI and finally embedded with cover glass. The cells were observed using a fluorescent microscope at an excitation of $355 \mathrm{~nm}$ and an emission of $450 \mathrm{~nm}$ for HEt and stained cells were counted as described above [17].

\section{In vivo model of Parkinson's disease \\ Subjects}

We used adult female Sprague-Dawley rats (Charles River, Japan) weighing 250-300 g at the beginning of the experiment, according to approved guidelines of the institutional animal care and use committee of Okayama University. They were housed two per cage in a temperature and humidity controlled room, maintained on a 12hour light/dark cycle, and they had free access to food and water.

\section{Surgical procedures}

Seventy eight rats were deeply anesthetized with sodium pentobarbital (30 mg/kg, i.p.) and placed in a stereotaxic instrument (Narishige, Japan). After pre-treatment of desipramine (25 mg/kg, i,p., Sigma), $20 \mu \mathrm{g}$ of 6-OHDA (4 $\mu \mathrm{l}$ of $5 \mu \mathrm{g} / \mu \mathrm{l}$ dissolved in saline containing $0.2 \mathrm{mg} / \mathrm{ml}$ ascorbic acid; Sigma) was injected into the right striatum with a 28-gauge Hamilton syringe into the following coordinates: $1.0 \mathrm{~mm}$ anterior to the bregma, $3.0 \mathrm{~mm}$ lateral to the sagittal suture, and $5.0 \mathrm{~mm}$ ventral to the surface of the brain with tooth-bar set at $0 \mathrm{~mm}$ [18]. The injection rate was $1 \mu \mathrm{l} /$ minute, and the syringe was left in place for an additional 5 minutes before being retracted slowly (1 $\mathrm{mm} /$ minute). At 30 minutes or 24 hours after 6-OHDA lesion, 30, 100, or $250 \mathrm{mg} / \mathrm{kg}$ of edaravone or saline (2
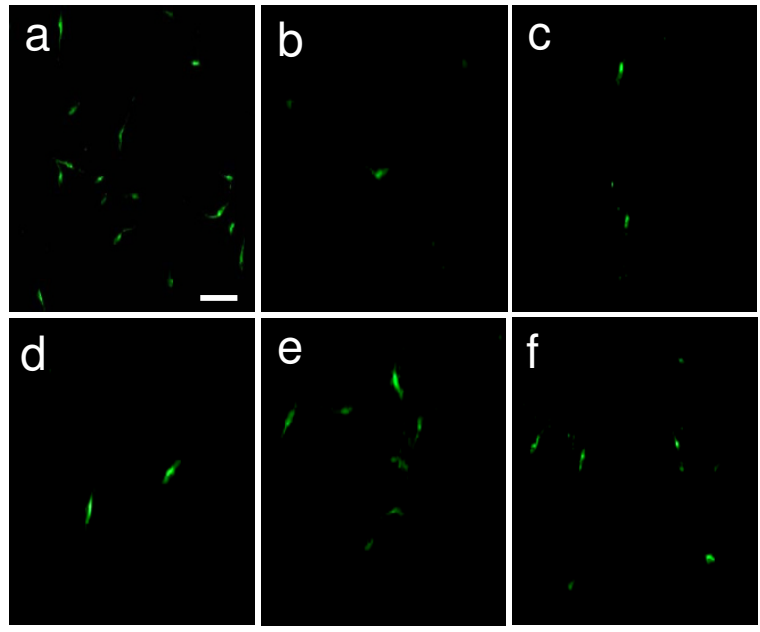

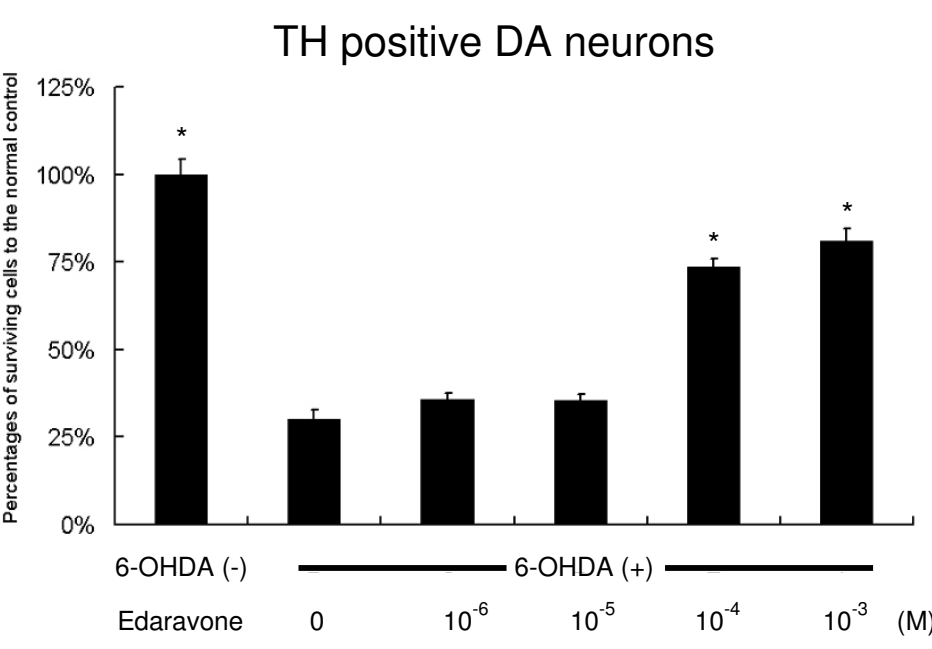

Figure I

Neuroprotective effects of edaravone on 6-OHDA-treated DA neurons in vitro. Left column: TH staining of DA neurons (a: non-6-OHDA-treated DA neurons) demonstrates that the number of surviving 6-OHDA-treated DA neurons significantly increased by the treatment with $10^{-4}$ and $10^{-3} \mathrm{M}$ edaravone (e and $\mathrm{f}$ ), compared to that with $10^{-6}$ and $10^{-5} \mathrm{M}$ (c and $\mathrm{d}$ ) edaravone as well as control without edaravone-administration (b). Scale bar: $30 \mu \mathrm{m}$. Right column: The graph demonstrates the number of surviving DA neurons by edaravone-administration. Data are shown as mean percentages of the cell number relative to the number of DA neurons without 6-OHDA-treatment +S.E. ${ }^{*} p<0.01$ vs. 6-OHDA-treated DA neurons without edaravone-administration and those with low dose edaravone $\left(10^{-6}\right.$ and $\left.10^{-5} \mathrm{M}\right)$ by ANOVA. 


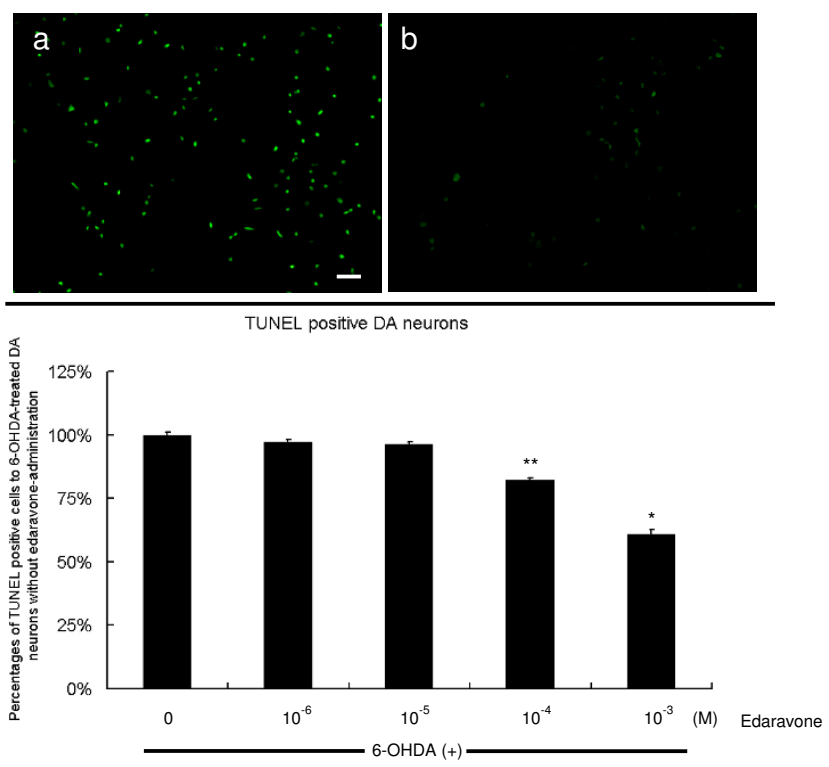

Figure 2

Reduced TUNEL-positive apoptotic 6-OHDAtreated DA neurons with edaravone-administration in vitro. Upper column: TUNEL-positive 6-OHDA-treated DA neurons with $10^{-3} \mathrm{M}$ edaravone (b) significantly decreased, compared to those without edaravone-administration (a). Scale bar: $60 \mu \mathrm{m}$. Lower column: The graph demonstrates that TUNEL-positive 6-OHDA-treated DA neurons decreased by $10^{-4}$ and $10^{-3} \mathrm{M}$ edaravone-administration. Data are shown as mean percentages of the cell number relative to the 6-OHDA-treated DA neurons without edaravone-administration + S.E. ${ }^{*} \mathrm{p}<0.01$ vs. 6 -OHDA-treated DA neurons without edaravone-administration and those with low dose edaravone $\left(10^{-6}\right.$ and $\left.10^{-5} \mathrm{M}\right)$ by ANOVA. ${ }^{* *} \mathrm{p}<$ 0.01 vs. 6-OHDA-treated DA neurons without edaravoneadministration.

$\mathrm{ml}$ ) were intravenously administered slowly from the right femoral vein.

\section{Behavioral testing}

All rats were tested with amphetamine $(2.5 \mathrm{mg} / \mathrm{kg}$, Dainippon-Seiyaku, Japan) at 1 and 2 weeks after 6-OHDA lesion, and rotational behaviors were assessed for $60 \mathrm{~min}$ utes with a video camera. Full 360 degrees turns in the direction ipsilateral to the lesion were counted.

\section{Fixation and Sectioning}

At 2 weeks after 6-OHDA lesion, rats were deeply anesthetized with sodium pentobarbital $(100 \mathrm{mg} / \mathrm{kg})$, perfused from the ascending aorta with $200 \mathrm{ml}$ of cold PBS, followed by $100 \mathrm{ml}$ of 4\% PFA in PBS. Brains were removed and post-fixed in the same fixative for 2 days followed by $30 \%$ sucrose in phosphate buffer (PB) until to be sunk completely. Six series of coronal sections were cut at a thickness of $40 \mu \mathrm{m}$ with a freezing microtome and stored at -20 degrees $\mathrm{C}$.

\section{Immunohistochemistry}

Free floating sections for TH immunohistochemistry were blocked by $0.3 \%$ hydroxygen peroxide in methanol for 3 minutes with subsequent incubation in $1.5 \%$ normal goat serum (Vector). Sections were then incubated overnight at 4 degrees $\mathrm{C}$ with rabbit anti-TH (1: 1,000; Chemicon) antibody with $10 \%$ normal goat serum. After several rinses in PBS, sections were incubated for 30 minutes in biotinylated donkey anti-rabbit IgG (1: 1,000, Jackson) then for 30 minutes in avidin-biotin-peroxidase complex (1: 200, Vector). Subsequently the sections were treated with 3, 4-diaminobenzidine (DAB, Sigma) and hydroxygen peroxide, mounted on albumin-coated slides and embedded with cover glass.

TUNEL and HEt staining were also performed to investigate the involvement of anti-apoptotic effects and radical scavenging activity of edaravone using 14 rats receiving saline or $250 \mathrm{mg} / \mathrm{kg}$ of edaravone-administration at 30 minutes after 6-OHDA lesioning and sacrificed at 5 days after 6-OHDA lesioning. Furthermore, in order to reveal the effects of edaravone on the inflammation induced by 6-OHDA-administration, immunofluorescent Iba-1 staining was also performed. Rabbit anti-Iba-1 antibody (1: 100, Wako Pure Chemical Industries, Osaka, Japan) was used as the primary antibody and Alexa Fluor 594 (Molecular Probes) as the secondary antibody.

\section{Morphological analysis}

The density of TH-positive fibers and Iba-1-positive microglia in the striatum of rats receiving edaravone- or saline-infusion was determined and analyzed as described previously with a computerized analysis system (Olympus Sp-1000, Japan) $[16,19]$ using 3 serial coronal section at the bregma level. Two areas adjacent to the needle tract of lesioned side and symmetrical contralateral side were analyzed, respectively. For counting the number of $\mathrm{TH}-$ positive neurons, every fifth $40 \mu \mathrm{m}$-thick coronal tissue section through the substantia nigra pars compacta (SNc) was explored using 3 coronal sections respectively at -4.8 and $-5.3 \mathrm{~mm}$ to the bregma. The number of TH-positive cell bodies in the SNc was counted and used for the statistical analyses.

\section{Statistical Analysis}

The data obtained were evaluated statistically using analysis of variance (ANOVA) and subsequent post hoc Scheffe's F-test or Mann-Whitney's U test. Statistical significance was preset at $\mathrm{p}<0.05$.

\section{Results}

\section{Edaravone promotes the survival of DA neurons in vitro}

We began our investigations into the neuroprotective capacity of edaravone on 6-OHDA-treated DA neurons in vitro. Exposure of $40 \mu \mathrm{M} 6$-OHDA resulted in a significant loss of TH-positive neurons to $30.2 \pm 2.5 \%$ relative to the 

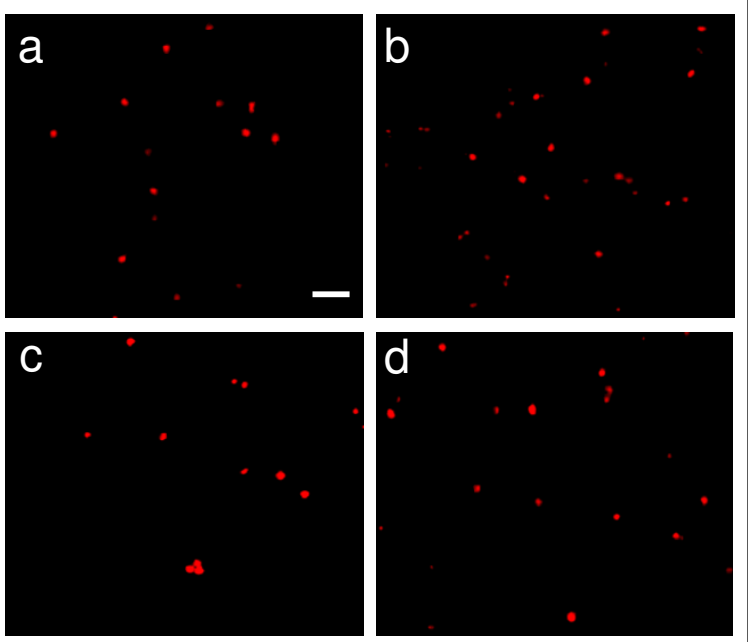

HEt-positive DA neurons with edaravone-administration

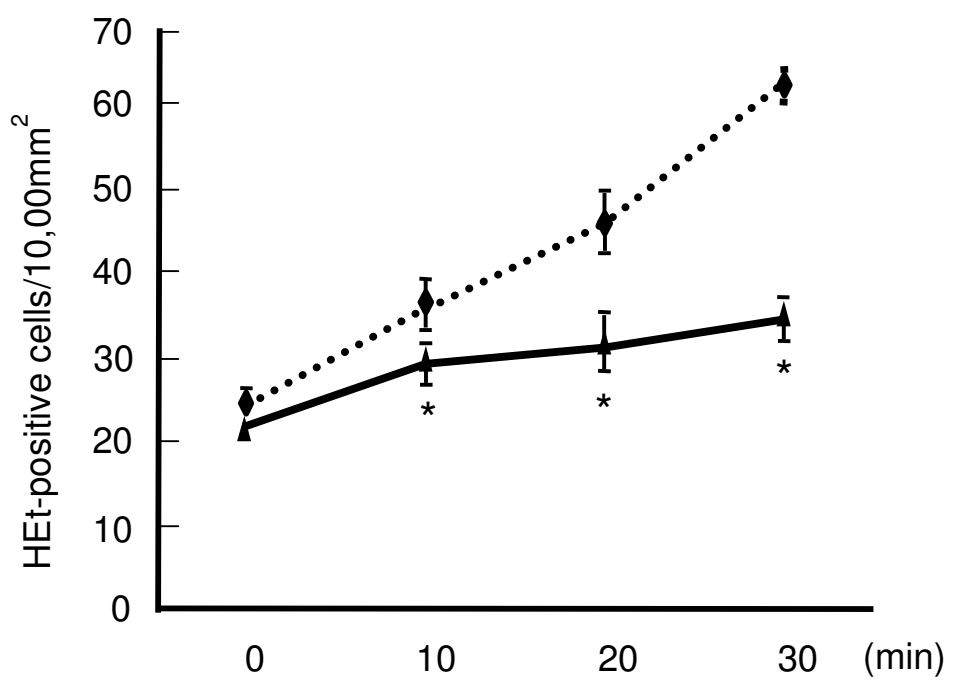

Figure 3

Reduced number of HEt-positive cells by edaravone-treatment in vitro. Left column: Edaravone treatment (I 0-3 $\mathrm{M})$ significantly reduced the number of $\mathrm{HEt}$-positive cells at 10,20,30 minutes after edaravone-administration, compared to the untreated 6-OHDA-exposed cells. (untreated 6-OHDA-treated DA neurons at 0 and 30 minutes (a and b); 6-OHDA-treated DA neurons with $10^{-3} \mathrm{M}$ edaravone at 0 and 30 minutes (c and d). Scale bar: $30 \mu \mathrm{m}$. Right column: The graph demonstrates that HEt-positive cells significantly decreased by edaravone-administration. Data are shown as the mean cell number \pm S.E. Dotted line: HEt-positive cells without edaravone, Full line: HEt-positive cells with $10^{-3} \mathrm{M}$ edaravone. ${ }^{*} \mathrm{p}<0.05$ vs. 6-OHDAtreated DA neurons without edaravone-administration by ANOVA.

unexposed control (Fig. 1). Edaravone-administration $\left(10^{-4}\right.$ and $\left.10^{-3} \mathrm{M}\right)$ significantly reduced the loss of DA neurons induced by 6 -OHDA $(81.1 \pm 3.5$ and $73.6 \pm 2.4 \%)$, compared to the 6-OHDA-treated DA neurons with $0,10^{-}$ ${ }^{6}$ and $10^{-5} \mathrm{M}$ edaravone, although $10^{-6}$ and $10^{-5} \mathrm{M}$ edaravone did not exert significant reduction of the cell loss $\left(35.4 \pm 1.9\right.$ and $35.8 \pm 1.7 \%$, One way ANOVA, $\mathrm{F}_{5,102}=$ 125, p $<0.0001$, Fig. 1).

In order to determine that edaravone suppressed cell death through apoptosis, DA neurons were exposed to 40 $\mu \mathrm{M} 6-\mathrm{OHDA}$ and then added $10^{-6}, 10^{-5}, 10^{-4}$ or $10^{-3} \mathrm{M}$ edaravone with subsequent counting the number of swelling apoptotic cells exhibiting agglutinated and fragmented TUNEL-positive nuclei. Edaravone treatment (10${ }^{3} \mathrm{M}$ ) significantly reduced the number of TUNEL-positive apoptotic cells to $60.9 \pm 1.7$ and $82.1 \pm 0.8 \%$ relative to that of 6-OHDA-treated DA neurons without edaravone treatment, although $10^{-6}$ and $10^{-5} \mathrm{M}$ did not suppress apoptosis $(96.2 \pm 0.7$ and $97.3 \pm 0.8 \%) \cdot 10^{-4} \mathrm{M}$ edaravone significantly suppressed apoptosis of DA neurons, compared to 6-OHDA-treated DA neurons without edaravone treatment (One way ANOVA, $\mathrm{F}_{4,45}=48$, $\mathrm{p}<0.0001$, Fig. 2).

In order to demonstrate the production of superoxide anions, HEt staining was performed. Edaravone treatment $\left(10^{-3} \mathrm{M}\right)$ significantly reduced the number of HEt-positive cells $(21.5 \pm 0.9,29 \pm 1.1,31 \pm 2.0$, and $34 \pm 1.7$ cells/ $10,000 \mu \mathrm{m}^{2}$ at $0,10,20$, and 30 minutes after edaravone administration), compared to the untreated 6-OHDAexposed cells $(24.3 \pm 1.7,35.7 \pm 1.7,45.7 \pm 3.3$, and 62.5 \pm 0.9 cells $/ 10,000 \mu^{2}$ at $0,10,20$, and 30 minutes, Repeated Measures of ANOVA, $\mathrm{F}_{3,18}=21, \mathrm{p}<0.0001$ and posthoc t-tests of p's $<0.01$ for 10,20 , and 30 minutes after edaravone-administration, Fig. 3)

\section{Behavioral analyses in vivo}

Next, we proceeded to the in vivo study using PD model of rats. There were no significant changes in the spontaneous behavior of rats receiving edaravone-administration at 30 minutes after 6-OHDA lesion $(30 \mathrm{mg} / \mathrm{kg}$ : determined by the dose for ischemic stroke) or saline (data not shown). As shown in Fig. 4, in PD model of rats receiving intravenous saline-infusion, the number of amphetamineinduced rotations increased over time at 1 and 2 weeks $(9.8 \pm 1.1$ and $11.1 \pm 0.6$ turns/hour $)$. However, rats receiving $250 \mathrm{mg} / \mathrm{kg}$ of edaravone-administration at 30 minutes after 6-OHDA lesion showed a significant reduction of the rotational number $(3.8 \pm 0.9$ and $2.3 \pm 0.7$ turns/hour at 1 and 2 weeks), although 30 and $100 \mathrm{mg} / \mathrm{kg}$ of edaravone did not exert significant effects $(30 \mathrm{mg} / \mathrm{kg}$ : $9.9 \pm 1.8$ and $10.4 \pm 1.9$ turns/hour, $100 \mathrm{mg} / \mathrm{kg}$ : $6.5 \pm 1.5$ and $7.0 \pm 1.4$ turns/hour at 1 and 2 weeks, Repeated Meas- 


\section{Amphetamine-induced rotational tests}
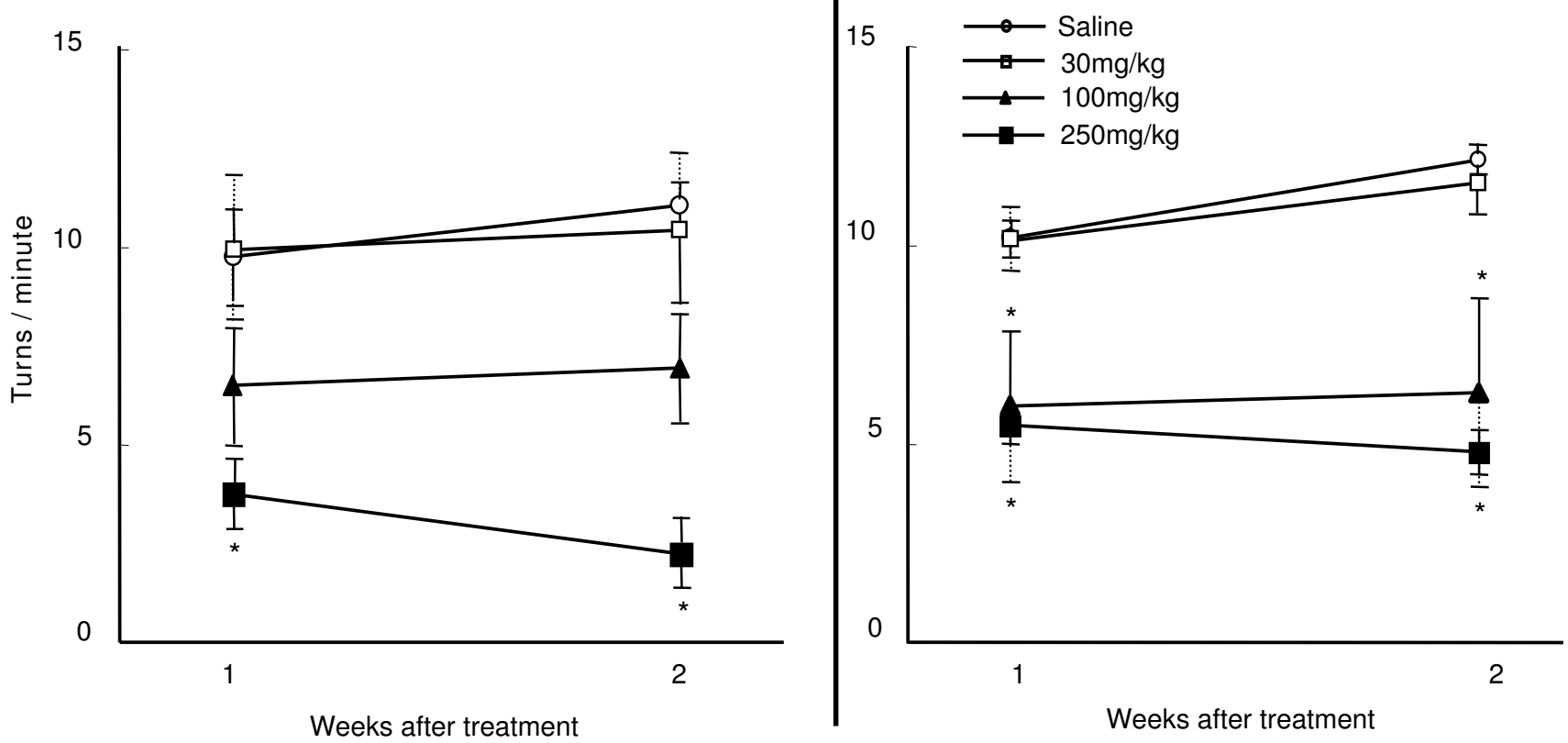

Figure 4

Edaravone ameliorated the amphetamine-induced rotational behavior of PD model of rats. Left graph: Rats receiving $250 \mathrm{mg} / \mathrm{kg}$ of edaravone infusion at 30 minutes after 6-OHDA lesion showed a significant reduction of the rotational number, although 30 and $100 \mathrm{mg} / \mathrm{kg}$ of edaravone did not exert significant effects. Data are shown as the mean rotational number per minute \pm S.E. ${ }^{*} p<0.05$ vs. rats receiving $30 \mathrm{mg} / \mathrm{kg}$ of edaravone and those without edaravone-administration. Right column: Edaravone administration $(250$ and $100 \mathrm{mg} / \mathrm{kg}$ ) at 24 hours after 6-OHDA lesion significantly suppressed the rotational behavior, compared to rats receiving saline. Data are shown as the mean rotational number per minute \pm S.E. ${ }^{*} \mathrm{p}<$ 0.05 vs. rats receiving $30 \mathrm{mg} / \mathrm{kg}$ of edaravone and those without edaravone-administration.

ures of ANOVA, $\mathrm{F}_{3,24}=8.8, \mathrm{p}<0.0001$ and posthoc t-tests of p's $<0.01$ for both time periods, Fig. 4).

After confirmation of neuroprotective effects of intravenous administration of edaravone $(250 \mathrm{mg} / \mathrm{kg})$ at $30 \mathrm{~min}-$ utes after 6-OHDA lesion on 6-OHDA-treated rats behaviorally, edaravone-administration at 24 hours were explored. Edaravone-administration (250 and $100 \mathrm{mg} /$ $\mathrm{kg}$ ) at 24 hours after 6-OHDA lesion significantly suppressed the rotational behavior $(250 \mathrm{mg} / \mathrm{kg}$ : $5.5 \pm 0.4$ and $4.3 \pm 0.6$ turns/hour, $100 \mathrm{mg} / \mathrm{kg}: 6.0 \pm 1.9$ and $6.3 \pm 2.4$ turns/hour at 1 and 2 weeks), compared to rats receiving saline $(10.2 \pm 0.8$ and $12.2 \pm 0.4$ turns/hour at 1 and 2 weeks, Repeated Measures of ANOVA, $\mathrm{F}_{3,22}=9.0, \mathrm{p}=$ 0.0005 and posthoc t-tests of p's $<0.01$ for both time periods, Fig. 4). Edaravone-administration ( $250 \mathrm{mg} / \mathrm{kg}$ ) at 30 minutes significantly ameliorated rotational behavior, compared to that at 24 hours after 6-OHDA lesion (Repeated Measures of ANOVA, $\mathrm{F}_{1,12}=4.5, \mathrm{p}=0.04$ and posthoc t-tests of p's $=0.04$ for both time periods). Thus, edaravone significantly ameliorated the rotational behav- ior when it was administered earlier and in higher concentration.

TH immunohistochemistry in the striatum and the SNc

At 2 weeks after edaravone-()administration, TH staining was performed to evaluate the preserved DA fibers in the striatum and DA neurons in the SNc (Fig. 5). The density of TH-positive fibers in the 6-OHDA-lesioned striatum was compared with the contralateral side using a modified method of computerized image analysis system [19]. The preservation of TH-positive fibers in the striatum of rats receiving edaravone was significantly greater (30 minutes: $23.3 \pm 1.5,41 \pm 1.2$ and $65.2 \pm 1.6 \% ; 24$ hours: 20.2 $\pm 0.9,38.2 \pm 1.7$ and $51.4 \pm 1.1 \%$ relative to the intact side at the dose of 30,100 and $250 \mathrm{mg} / \mathrm{kg}$, respectively) than those receiving the saline (30 minutes: $12.1 \pm 0.5,24$ hours: $8.9 \pm 0.3 \%$, Repeated Measures of ANOVA, $\mathrm{F}_{3,16}=$ $425, \mathrm{p}<0.0001$ and posthoc t-tests of p's $<0.01$ for all groups, Fig. 6).

The number of TH-positive neurons in the ipsilateral SNc of rats was analyzed as percentages relative to the number 

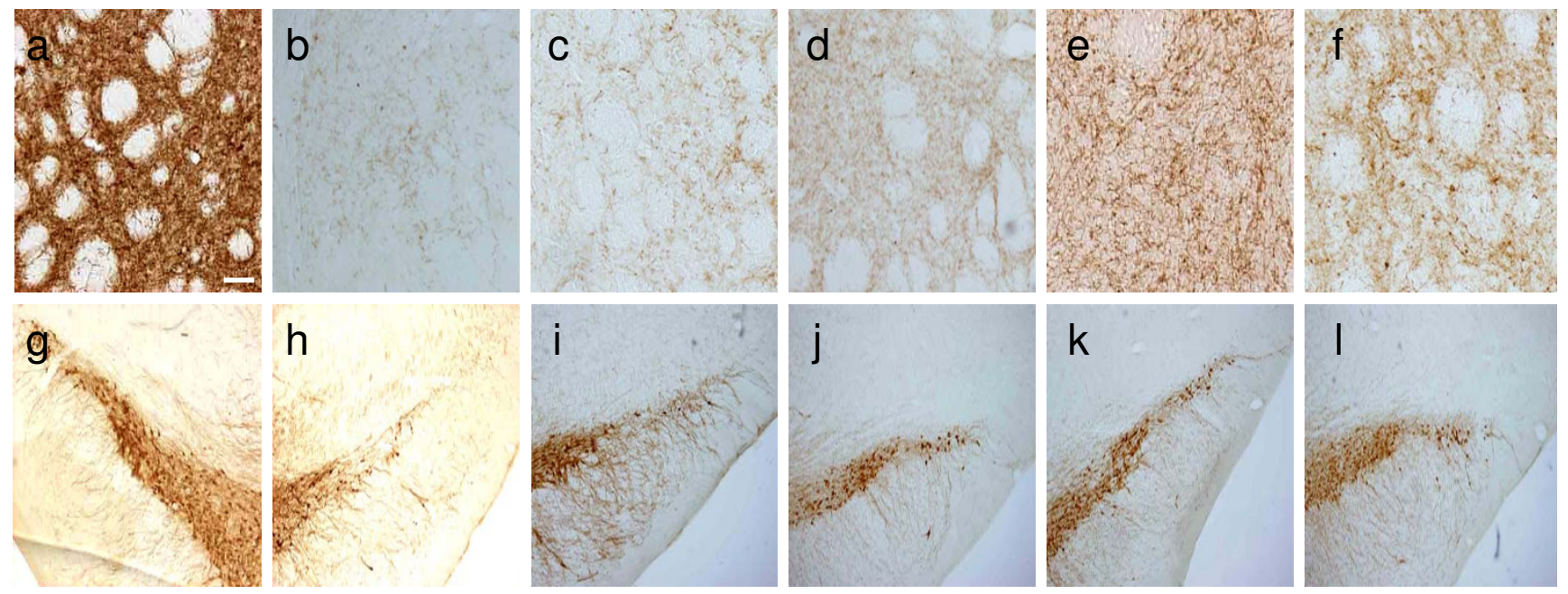

\section{Figure 5}

Preserved TH-positive fibers in the striatum and neurons in the SNc of rats receiving edaravone-administration. Photomicrographs demonstrate that 100 and $250 \mathrm{mg} / \mathrm{kg}$ of edaravone preserved TH immunoreactivity in the striatum and SNc (edaravone-administration at 30 minutes after 6-OHDA lesion, $30 \mathrm{mg} / \mathrm{kg}: \mathrm{c}$ and i, $100 \mathrm{mg} / \mathrm{kg}: \mathrm{d}$ and J, $250 \mathrm{mg} / \mathrm{kg}$ : e and k, edaravone administration at 24 hours after 6-OHDA lesion, $250 \mathrm{mg} / \mathrm{kg}: \mathrm{f}$ and l), compared to the untreated 6-OHDA-

lesioned rats $(b$ and $h)$. TH staining of the intact side of the striatum and SNc: a and $h, T H$ staining of the striatum: a-f, and the SNc: g-I. Scale bar: $120 \mu \mathrm{m}$ in a-f, $480 \mu \mathrm{m}$ in g-l.

of counted DA neurons in the intact side. The preservation of TH-positive neurons in the SNc of rats receiving edaravone (100 and $250 \mathrm{mg} / \mathrm{kg}$ ) was significantly greater (30 minutes: $18.5 \pm 1.4,33.5 \pm 1.4$ and $53.9 \pm 1.4 \%$; 24 hours: $16.4 \pm 0.9,31.8 \pm 1.0$ and $48.3 \pm 2.3 \%$ relative to the intact side at the dose of 30,100 and $250 \mathrm{mg} / \mathrm{kg}$, respectively) than those receiving the saline (30 minutes: $12.8 \pm 1.6,24$ hours: $15 \pm 0.8 \%$, Repeated Measures of ANOVA, $F_{3,16}=$ $324, \mathrm{p}<0.0001$ and posthoc t-tests of p's $<0.01$, Fig. 6). DA fibers in the striatum of rats receiving edaravone at 30 minutes after 6-OHDA lesion was significantly preserved, compared to those with edaravone-administration at 24 hours (p's $<0.001$ ), although DA neurons in the SNc of both time periods were not significantly different ( $\mathrm{p}$ 's $=$ $0.11)$.

\section{TUNEL and HEt staining for anti-apoptotic and anti- oxidative effects}

The percentages of TUNEL positive cells in the SNc of rats receiving $250 \mathrm{mg} / \mathrm{kg}$ of edaravone at 30 minutes after 6 OHDA lesion significantly decreased $(9.6 \pm 1.0 \%)$, compared to those of rats without edaravone treatment (26.7 $\pm 5.7 \%$, Repeated Measures of ANOVA, $\mathrm{F}_{1,12}=3.4, \mathrm{p}=$ 0.034 and posthoc t-tests of p's $<0.05$, Fig. 7). The percentages of TH and HEt double positive cells per TH positive cells of rats receiving $250 \mathrm{mg} / \mathrm{kg}$ of edaravone at 30 minutes after 6-OHDA lesion significantly decreased $(12.9 \pm 1.5 \%)$, compared to those of rats without edaravone treatment $(37.7 \pm 3.4 \%$, Repeated Measures of ANOVA, $\mathrm{F}_{1,12}=32, \mathrm{p}<0.001$ and posthoc t-tests of p's $<$ 0.05, Fig. 7).

\section{Iba-I immunohistochemistry for the affected inflammation}

Iba-1 staining was performed to evaluate anti-inflammatory effects of edaravone through the microglia. Edaravone administration $(250 \mathrm{mg} / \mathrm{kg})$ at 30 minutes after 6 OHDA lesion significantly suppressed the number of Iba1-positive cells $\left(178 \pm 4.2\right.$ cells $/ 10,000 \mu \mathrm{m}^{2}$; non-edaravone-administered group: $252 \pm 14$ cells $/ 10,000 \mu \mathrm{m}^{2}$ ), thus indicating that edaravone suppressed inflammation induced by 6-OHDA with the decrease of activated microglia ( $<<0.05$, Mann-Whitney's U test, Fig. 8).

\section{Discussion}

In this study, neuroprotective effects of edaravone on 6OHDA-treated murine ventral mesencephalic DA neurons were clarified in vitro. Anti-apoptotic effects through scavenging radicals might play an important role in the underlying mechanisms of neuroprotective effects of edaravone. In parallel, neuroprotective effects of edaravone on 6OHDA-lesioned PD model of rats were demonstrated behaviorally and immunohistochemically. Edaravone might exert the neuroprotective effects on DA neurons. TUNEL, HEt and Iba-1 staining suggested the involvement of anti-apoptotic, anti-oxidative and anti-inflammatory effects of edaravone.

\section{Anti-apoptotic effects of edaravone}

Neuroprotective effects of edaravone might be mediated by anti-apoptotic effects. Against ischemic reperfusion, edaravone prevents cell death and the release of cytochrome $\mathrm{c}$ with subsequent pathological apoptosis 


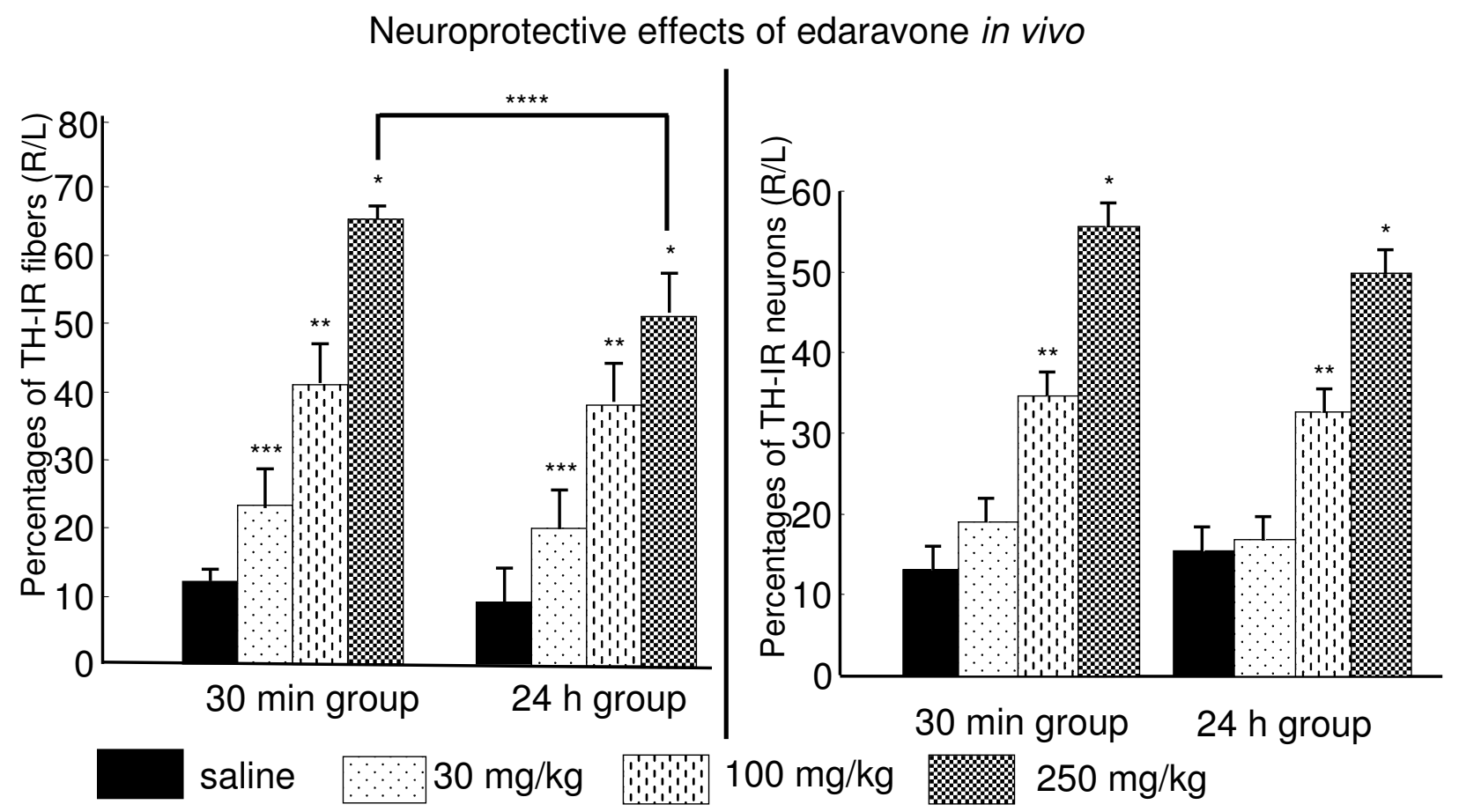

\section{Figure 6}

Edaravone-administration exerted neuroprotective effects in a dose-responsive manner immunohistochemically in vivo. Left graph: TH staining of the striatum demonstrates neuroprotective effects of edaravone on 6-OHDA-lesioned striatal DA fibers in a dose-responsive manner. Data are shown as the percentages of TH-positive fibers relative to the intact side \pm S.E. ${ }^{*} p<0.05$ vs. rats in all other groups, ${ }^{*}$ p $<0.05$ vs. rats receiving $30 \mathrm{mg} / \mathrm{kg}$ of edaravone and those without edaravone-administration, $* * *$ p $<0.05$ vs. rats without edaravone-administration, $* * * *$ p $<0.05$ (rats receiving edaravone at 30 minutes after 6-OHDA lesion ( $30 \mathrm{~min}$ group) vs. rats with edaravone at 24 hours ( $24 \mathrm{~h}$ group)). Right graph: TH staining of the SNc demonstrates neuroprotective effects of edaravone on 6-OHDA-lesioned striatal DA fibers in a dose-responsive manner. Data are shown as the percentages of TH-positive neurons relative to the intact side \pm S.E. * $p<0.05$ vs. rats in all other groups, ${ }^{* *} \mathrm{p}<0.05 \mathrm{vs}$. rats receiving $30 \mathrm{mg} / \mathrm{kg}$ of edaravone and those without edaravone-administration.

through Bcl-2 upregulation by inhibiting the opening of the mitochondrial permeability transposition pore $[20,21]$. In parallel, edaravone might reduce Fas-associated death domain protein and subsequently suppress apoptotic cell death in cerebral infarct [22]. Furthermore, edaravone might alleviate dysfunction of endoplasmic reticulum with subsequent cell death in cerebral ischemia [23]. Edaravone also reduces nitric oxide-induced apoptosis by inhibiting activation of MAP kinase in astroctes [24]. Related to 6-OHDA-toxicity, apoptosis is induced by down-regulation of Bcl-2 with activation of caspases in thymocytes [25], which might be suppressed by edaravone. Activated microglia damages surrounding cells by the paracrine of various cytokines. Using co-culture of neuronal cells and microglia, neuronal cell death by the peroxynitrite donor, SIN-1 (N-morpholinosydnonimine) is significantly suppressed by $10^{-4} \mathrm{M}$ edaravone [15]. In our study, the number of TUNEL-positive apoptotic cells and HEt-positive cells decreased using both in vitro and in vivo model of PD. The number of activated microglia of rats receiving $250 \mathrm{mg} / \mathrm{kg}$ of edaravone decreased, suggesting that the reduced cytotoxic cytokines might suppress apoptosis synergistically. The underlying mechanisms of the neuroprotection of edaravone might be involved in the hypothesis above described.

\section{Characteristics of our study}

Recently, the similar study was reported using 1-methyl-4phenyl-1,2,3,6-tetrahydropyridine (MPTP)-treated mice [26]. MPTP activated microglial activation both in the striatum and SNc with the increase of 3-nitrotyrosine, a biomarker of peroxynitrite production, in the SNc, but not in the striatum. Intraperitoneal $3 \mathrm{mg} / \mathrm{kg}$ of edaravone significantly ameliorate the behavioral scores, however the neuroprotective effects might be limited in the SNc. Using the animal model of cerebral infarct and head trauma, Dohi and colleagues also demonstrated the neuroprotective effects of low dose of edaravone [13]. In our study, the neuroprotective effects of edaravone (100 and $250 \mathrm{mg} / \mathrm{kg}$ ) was demonstrated both in the striatum and 

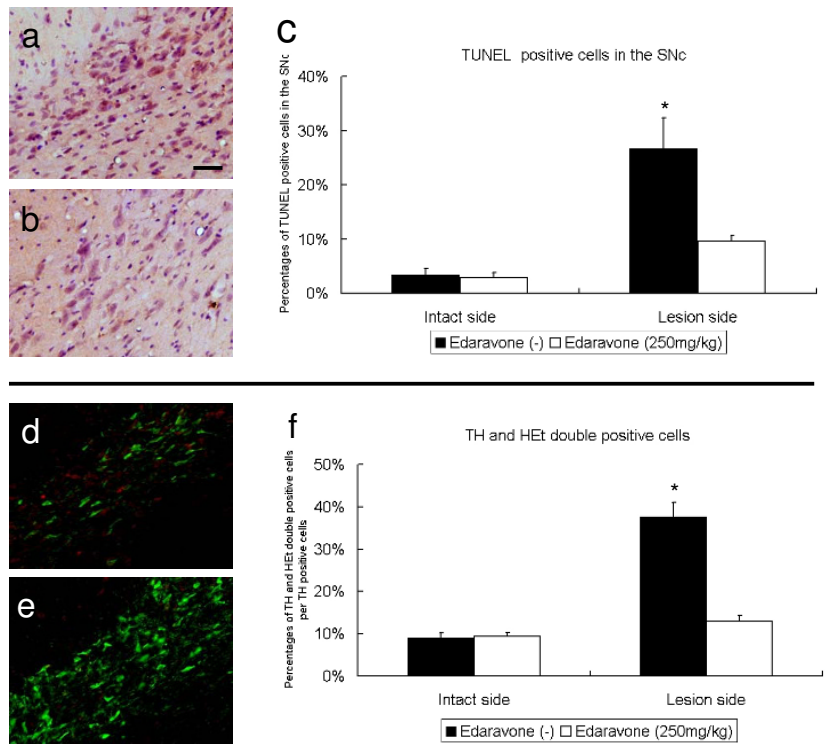

Figure 7

Anti-apoptotic and anti-oxidative effects of edaravone. Upper column: TUNEL staining revealed that edaravone administration $(250 \mathrm{mg} / \mathrm{kg})$ at 30 minutes after 6 OHDA lesion significantly decreased the percentages of TUNEL positive cells in the SNc (b), compared to rats without edaravone-administration (a). Scale bar: $60 \mu \mathrm{m}$ The graph demonstrates the significant differences (c). Data are shown as the percentages of TUNEL positive cells +S.E. *p $<0.05$ vs. the lesion side of edaravone-administered rats and the intact side. Lower column: TH and HEt double staining revealed that edaravone administration $(250 \mathrm{mg} / \mathrm{kg})$ at 30 minutes after 6-OHDA lesion significantly decreased the percentages of $\mathrm{TH}$ and $\mathrm{HEt}$ double positive cells (e), compared to rats without edaravone-administration (d; green: $\mathrm{TH}$, red: HEt; Scale bar: $60 \mu \mathrm{m}$ ). The graph demonstrates the significant differences (f). Data are shown as the percentages of HEt positive cells + S.E. * $p<0.05$ vs. the lesion side of edaravoneadministered rats and the intact side.

SNc, although $30 \mathrm{mg} / \mathrm{kg}$ did not exert any neuroprotective effects, except for the histological amelioration in the striatum. Additionally, the behavioral amelioration by $100 \mathrm{mg} / \mathrm{kg}$ of edaravone-administered at 30 minutes and 24 hours after 6-OHDA lesioning did not show timedependency. Furthermore, the lower dosage of edaravone ( 3 and $10 \mathrm{mg} / \mathrm{kg}$ ) exerted no neuroprotective effects in our pilot study (data not shown). These discrepancies of the results might be due to the alteration of edaravoneactivity and affinity over time after lesioning, the characteristics of the behavioral test, or the differences of the toxin (MPTP vs. 6-OHDA), of the administration route (i.p. vs. i.v.), of the animal species (mice vs. rat), and of the detailed regimen. For the safe clinical application, some amelioration of the drug, including the enhanced action for neurons specifically, because edaravone-admin- istration even at clinical dosage might result in severe side effects [27].

Until now several studies demonstrated neuroprotective effects of pre-treatment of edaravone against metamphetamine-toxicity on striatal dopaminergic degeneration [28] and post-ischemic dopaminergic dysfunctions [29]. One of the remarkable characteristics of our study also lie in the time-dependent effects of edaravone, that is, the earlier (at 30 minutes after 6-OHDA lesion) administration might exert significantly stronger neuroprotective effects than the later one (at 24 hours), mimicking the clinical settings, although the later administration still displayed the behavioral and histological amelioration. In the future, the effects of repeated administration of edaravone on PD model should be clarified.

\section{Therapy for PD in the future including edaravone- administration}

The established therapy for PD is medication using LDOPA (dihydroxyphenylalanine), DA agonist and various drugs of different mechanisms, surgeries including electrical stimulation and ablation [30]. Fetal cell transplantation and GDNF infusion [31] are also hopeful, although the recent double-blinded randomized controlled trials questioned us the efficacy of these therapy $[32,33]$. In the nearest preceding years, neural transplantation might be a hopeful therapeutic option for PD [34] with recent development in the stem cell biology [35-40]. When edaravone is used for PD patients, several advantages might be recognized in combination with other therapeutic options. As edaravone extends the therapeutic time window for ischemic patients in combination with tissue plasminogen activator [41], edaravone might ameliorate the survival of transplanted cells [42] as well as scavenge free radicals in PD. Edaravone might also suppress inflammatory reaction induced by surgical procedures including electrical stimulation and cell transplantation.

\section{Conclusion}

Neuroprotective effects of edaravone on 6-OHDA-treated DA neurons were clarified in vitro. Anti-apoptotic effects and radical scavenging activity might be involved in the underlying mechanisms of neuroprotective effects of edaravone. Neuroprotective effects of edaravone were then demonstrated using animal model of PD. Edaravone might be a hopeful therapeutic option for PD, although several critical issues remain to be solved, including high therapeutic dosage of edaravone for the safe clinical application in the future.

\section{Authors' contributions}

WJY is involved in acquisition of data and drafting the manuscript. TS, TY, TA and ID designed the study, ana- 
lyzed the data and revised the manuscript. KM, MK and YM performed in vivo experiments including surgeries and animal care. TU, TM and MJ performed in vitro experiments including immunocytochemical investigations. NT and $\mathrm{TB}$ performed immunohistochemical investigations. FW and LH performed additional experiments in the revised manuscript. All authors read and approved the final manuscript.

\section{Acknowledgements}

This work was supported in part by Grants-in-Aid for Scientific Research and by the grant from the Project for realization of regenerative medicine from the Ministry of Education, Culture, Sports, Science, and Technology, Japan.

\section{References}

I. Noelker C, Bacher M, Gocke P, Wei X, Klockgether T, Du Y, Dodel $\mathrm{R}$ : The flavanoide caffeic acid phenethyl ester blocks 6hydroxydopamine-induced neurotoxicity. Neuroscience letters 2005, 383(I-2):39-43.

2. Blum D, Torch S, Lambeng N, Nissou M, Benabid AL, Sadoul R, Verna JM: Molecular pathways involved in the neurotoxicity of 6OHDA, dopamine and MPTP: contribution to the apoptotic theory in Parkinson's disease. Prog Neurobiol 200I, 65(2): $135-172$.

3. Fornstedt B, Rosengren E, Carlsson A: Occurrence and distribution of 5-S-cysteinyl derivatives of dopamine, dopa and dopac in the brains of eight mammalian species. Neuropharmacology 1986, 25(4):45I-454.

4. Maruyama W, Youdim MB, Naoi M: Antiapoptotic properties of rasagiline, $\mathbf{N}$-propargylamine-I(R)-aminoindan, and its optical (S)-isomer, TV 1022. Annals of the New York Academy of Sciences 200I, 939:320-329.

5. Nie G, Jin C, Cao Y, Shen S, Zhao B: Distinct effects of tea catechins on 6-hydroxydopamine-induced apoptosis in $\mathrm{PCI} 2$ cells. Archives of biochemistry and biophysics 2002, 397(1):84-90.

6. Yasuhara T, Shingo T, Date I: The potential role of vascular endothelial growth factor in the central nervous system. Reviews in the neurosciences 2004, 15(4):293-307.

7. Borlongan CV, Sanberg PR: Elevated body swing test: a new behavioral parameter for rats with 6-hydroxydopamineinduced hemiparkinsonism. J Neurosci 1995, I5(7 Pt 2):5372-5378.

8. Thakar JH, Hassan MN: Effects of 6-hydroxydopamine on oxidative phosphorylation of mitochondria from rat striatum, cortex, and liver. Can J Physiol Pharmacol 1988, 66(4):376-379.

9. Galindo MF, Jordan J, Gonzalez-Garcia C, Cena V: Chromaffin cell death induced by 6-hydroxydopamine is independent of mitochondrial swelling and caspase activation. Journal of neurochemistry 2003, 84(5): 1066-1073.

10. Kawai H, Nakai H, Suga M, Yuki S, Watanabe T, Saito KI: Effects of a novel free radical scavenger, $\mathrm{MCl}-186$, on ischemic brain damage in the rat distal middle cerebral artery occlusion model. J Pharmacol Exp Ther 1997, 28 I(2):921-927.

II. Shichinohe H, Kuroda S, Yasuda H, Ishikawa T, Iwai M, Horiuchi M, Iwasaki Y: Neuroprotective effects of the free radical scavenger Edaravone (MCl-186) in mice permanent focal brain ischemia. Brain research 2004, 1029(2):200-206.

12. Bates B, Hirt L, Thomas SS, Akbarian S, Le D, Amin-Hanjani S, Whalen M, Jaenisch R, Moskowitz MA: Neurotrophin-3 promotes cell death induced in cerebral ischemia, oxygen-glucose deprivation, and oxidative stress: possible involvement of oxygen free radicals. Neurobiology of disease 2002, 9(1):24-37.

13. Dohi K, Satoh K, Nakamachi T, Yofu S, Hiratsuka K, Nakamura S, Ohtaki H, Yoshikawa T, Shioda S, Aruga T: Does edaravone (MCl186) act as an antioxidant and a neuroprotector in experimental traumatic brain injury? Antioxidants \& redox signaling 2007, 9(2):28I-287.

14. Takahashi G, Sakurai M, Abe K, Itoyama Y, Tabayashi K: MCI-I86 reduces oxidative cellular damage and increases DNA repair function in the rabbit spinal cord after transient ischemia. The Annals of thoracic surgery 2004, 78(2):602-607.

15. Banno M, Mizuno T, Kato H, Zhang G, Kawanokuchi J, Wang J, Kuno $R$, Jin $S$, Takeuchi $H$, Suzumura $A$ : The radical scavenger edaravone prevents oxidative neurotoxicity induced by peroxynitrite and activated microglia. Neuropharmacology 2005, 48(2):283-290.

16. Yasuhara T, Shingo T, Kobayashi K, Takeuchi A, Yano A, Muraoka K, Matsui T, Miyoshi Y, Hamada H, Date I: Neuroprotective effects of vascular endothelial growth factor (VEGF) upon dopaminergic neurons in a rat model of Parkinson's disease. The European journal of neuroscience 2004, I 9(6): | 494-I504.

17. Liu J, Narasimhan P, Lee YS, Song YS, Endo H, Yu F, Chan PH: Mild hypoxia promotes survival and proliferation of SOD2-deficient astrocytes via c-Myc activation. J Neurosci 2006, 26(16):4329-4337

18. Paxinos GWG: The Rat Brain in Stereotaxic Coordinates 4th edition. San Diego: Academic Press; 1998.

19. Date I, Felten SY, Olschowka JA, Felten DL: Limited recovery of striatal dopaminergic fibers by adrenal medullary grafts in MPTP-treated aging mice. Experimental neurology 1990, 107(3): 197-207.

20. Rajesh KG, Sasaguri S, Suzuki R, Maeda H: Antioxidant $\mathbf{M C l}-186$ inhibits mitochondrial permeability transition pore and upregulates Bcl-2 expression. American journal of physiology 2003, 285(5): $\mathrm{H} 2|7|-2 \mid 78$

21. Takayasu Y, Nakaki J, Kawasaki T, Koda K, Ago Y, Baba A, Matsuda $\mathrm{T}$ : Edaravone, a radical scavenger, inhibits mitochondrial permeability transition pore in rat brain. Journal of pharmacological sciences 2007, I03(4):434-437.

22. Xiao B, Bi FF, Hu YQ, Tian FF, Wu ZG, Mujlli HM, Ding L, Zhou XF: Edaravone neuroprotection effected by suppressing the gene expression of the Fas signal pathway following transient focal ischemia in rats. Neurotox Res 2007, I 2(3): $155-162$.

23. Qi X, Okuma Y, Hosoi T, Nomura Y: Edaravone protects against hypoxia/ischemia-induced endoplasmic reticulum dysfunction. The Journal of pharmacology and experimental therapeutics 2004, 3 II(I):388-393.

24. Kawasaki T, Kitao T, Nakagawa K, Fujisaki H, Takegawa $Y$, Koda K, Ago Y, Baba A, Matsuda T: Nitric oxide-induced apoptosis in cultured rat astrocytes: protection by edaravone, a radical scavenger. Glia 2007, 55(13): 1325-1333.

25. Tsao CW, Cheng JT, Lin YS: Down-regulation of Bcl-2, activation of caspases, and involvement of reactive oxygen species in 6-hydroxydopamine-induced thymocyte apoptosis. Neuroimmunomodulation 2002, I0(6):328-336.

26. Kawasaki T, Ishihara K, Ago Y, Baba A, Matsuda T: Edaravone (3methyl-I-phenyl-2-pyrazolin-5-one), a radical scavenger, prevents I-methyl-4-phenyl-I,2,3,6-tetrahydropyridineinduced neurotoxicity in the substantia nigra but not the striatum. The Journal of pharmacology and experimental therapeutics 2007, 322(1):274-281

27. Abe M, Kaizu K, Matsumoto K: A case report of acute renal failure and fulminant hepatitis associated with edaravone administration in a cerebral infarction patient. Ther Apher Dial 2007, I I (3):235-240.

28. Kawasaki T, Ishihara K, Ago Y, Nakamura S, Itoh S, Baba A, Matsuda $\mathrm{T}$ : Protective effect of the radical scavenger edaravone against methamphetamine-induced dopaminergic neurotoxicity in mouse striatum. European journal of pharmacology 2006, 542(I-3):92-99

29. Akiyama Y, Miwa S: Improvement of postischemic dopaminergic dysfunction by edaravone, a free radical scavenger. Journal of pharmacological sciences 2007, 104(I):99-102.

30. Kumar R, Lozano AM, Kim YJ, Hutchison WD, Sime E, Halket E, Lang $A E$ : Double-blind evaluation of subthalamic nucleus deep brain stimulation in advanced Parkinson's disease. Neurology I 998, 5 I (3):850-855.

31. Patel NK, Bunnage M, Plaha P, Svendsen CN, Heywood P, Gill SS: Intraputamenal infusion of glial cell line-derived neurotrophic factor in PD: a two-year outcome study. Ann Neurol 2005, 57(2):298-302.

32. Freed CR, Greene PE, Breeze RE, Tsai WY, DuMouchel W, Kao R, Dillon S, Winfield H, Culver S, Trojanowski JQ, et al.: Transplantation of embryonic dopamine neurons for severe Parkinson's disease. N Engl J Med 200I, 344( I 0):710-7I 9. 
33. Olanow CW, Goetz CG, Kordower JH, Stoessl AJ, Sossi V, Brin MF, Shannon KM, Nauert GM, Perl DP, Godbold J, et al.: A double-blind controlled trial of bilateral fetal nigral transplantation in Parkinson's disease. Ann Neurol 2003, 54(3):403-4I4.

34. Borlongan CV, Sanberg PR, Freeman TB: Neural transplantation for neurodegenerative disorders. Lancet 1999, 353(Suppl I):SI29-30.

35. Dezawa M, Kanno H, Hoshino M, Cho H, Matsumoto N, Itokazu Y, Tajima N, Yamada $H$, Sawada $H$, Ishikawa $H$, et al.: Specific induction of neuronal cells from bone marrow stromal cells and application for autologous transplantation. The Journal of clinical investigation 2004, I I3( | 2): 170|-1710.

36. Takagi Y, Takahashi J, Saiki H, Morizane A, Hayashi T, Kishi Y, Fukuda $\mathrm{H}$, Okamoto $\mathrm{Y}$, Koyanagi M, Ideguchi M, et al.: Dopaminergic neurons generated from monkey embryonic stem cells function in a Parkinson primate model. The Journal of clinical investigation 2005, II 5(I): 102-109.

37. Yasuhara T, Matsukawa N, Hara K, Yu G, Xu L, Maki M, Kim SU, Borlongan $C V$ : Transplantation of human neural stem cells exerts neuroprotection in a rat model of Parkinson's disease. J Neurosci 2006, 26(48): | 2497- |25II.

38. Takahashi K, Yamanaka S: Induction of pluripotent stem cells from mouse embryonic and adult fibroblast cultures by defined factors. Cell 2006, I 26(4):663-676.

39. Redmond DE Jr, Bjugstad KB, Teng YD, Ourednik V, Ourednik J, Wakeman DR, Parsons XH, Gonzalez R, Blanchard BC, Kim SU, et al.: Behavioral improvement in a primate Parkinson's model is associated with multiple homeostatic effects of human neural stem cells. Proceedings of the National Academy of Sciences of the United States of America 2007, 104(29): 12175-12180.

40. Muraoka K, Shingo T, Yasuhara T, Kameda M, Yuen WJ, Uozumi T, Matsui T, Miyoshi Y, Date I: Comparison of the therapeutic potential of adult and embryonic neural precursor cells in a rat model of Parkinson disease. Journal of neurosurgery 2008, I08(I): I49-159.

4I. Zhang W, Sato K, Hayashi T, Omori N, Nagano I, Kato S, Horiuchi S, Abe K: Extension of ischemic therapeutic time window by a free radical scavenger, Edaravone, reperfused with tPA in rat brain. Neurological research 2004, 26(3):342-348.

42. Nelson SK, Bose S, Rizeq M, McCord JM: Oxidative stress in organ preservation: a multifaceted approach to cardioplegia. Biomedicine \& pharmacotherapy = Biomedecine \& pharmacotherapie 2005, 59(4): $149-157$.

Publish with Bio Med Central and every scientist can read your work free of charge

"BioMed Central will be the most significant development for disseminating the results of biomedical research in our lifetime. " Sir Paul Nurse, Cancer Research UK

Your research papers will be:

- available free of charge to the entire biomedical community

- peer reviewed and published immediately upon acceptance

- cited in PubMed and archived on PubMed Central

- yours - you keep the copyright

Submit your manuscript here:

http://www.biomedcentral.com/info/publishing_adv.asp
BioMedcentral

Page 11 of 11 